duas naturezas, por outro falamos em uma só cultura. Uma cultura da relação e em relação. Nesta cultura narrativa e intersubjetiva situamos a possibilidade de diálogo entre humanos e não humanos e tornamos viável falar em termos de reconhecimento interespecífico" (:150).

Ora, se o perspectivismo tem valência para pensar a relação entre primatas e primatólogos, Sá observa que neste caso também está presente uma relação de predação. Desta vez predação científica, que transforma o sujeito primata em objeto primata, por meio de um processo de purificação que delineia a transformação de uma relação de reconhecimento em uma relação de conhecimento (:161).

Seguindo a linha de argumentação do autor, tal processo de predação, a partir do qual "o primatólogo transforma o seu interlocutor primata de sujeito em objeto" (:166), não é descrito nos termos de uma representação, mas sim na forma de uma transubstanciação que visa estabelecer "níveis seguros de alteridade como condição" (:161). Os carinhos, os afetos, as interafecções do campo devem ficar lá; o primata da/na mata não é o mesmo que aparece nos artigos e nas publicações científicas. Vale observar, contudo, que a noção de predação científica aportada pelo autor contém outra dimensão. Ela se faz necessária para evitar - no caso extremo de Dian Fossey - a morte propriamente física, ou social, científica (:159).

As relações entre natureza e cultura também são temas que atravessam os argumentos contidos no livro. Elas aparecem, por exemplo, quando o autor explora uma controvérsia envolvendo fazendeiros das redondezas e os biólogos da Estação a respeito da invasão dos muriquis às plantações de milho. Formamse os seguintes pares: para os biólogos, lugar de macaco é na mata e comida de macaco é vegetação nativa. Já para os fazendeiros, que viam suas plantações de milho serem "atacadas" pelos macacos, estes poderiam muito bem se alimentar de milho, com espécimes introduzidos na mata, para evitar a busca por ele fora de seus limites. Assim, para os biólogos, "comida de gente deve ser naturalmente diferente de comida de bicho" (:96, grifo do autor), ao passo que o fazendeiro, de certa forma, acaba por culturalizar o animal, oferecendo a ele a opção de escolha. A fixidez de nossas - aí englobando cientistas e fazendeiros - categorias de natureza e cultura mostra-se estremecida neste exemplo e revela-se ainda de forma mais contundente e basilar no capítulo final da obra.

O desafio que o autor percebe, juntamente com os primatas e os primatólogos que se fazem presentes em seu texto, é como escapar das armadilhas da projeção culturalista pensando os símios não como equivalentes estruturais das culturas dos seres humanos homo sapiens. Seguindo sua intuição, Sá conclui que "os animais foram sempre seres culturais [...] porque há muito estão inseridos em relações sociais" (:190). São as relações que aqui importam, e não os seus termos humano e não humano.

SPEDDING, Alison. 2011. Sueños, kharisiris y curanderos: dinámicas sociales de las creencias en los Andes contemporáneos. La Paz: Editorial Mama Huaco. 205 pp.

\section{Indira Viana Caballero}

PPGAS/MN/UFRJ

Esta coletânea é composta por seis artigos que tratam de diferentes aspectos da "religião popular" (:9) nos Andes. Os procedimentos rituais religiosos apresentam traços daquilo que é chamado de "tradicional andino", do cristianismo e de uma 
mescla de elementos modernos, urbanos e ocidentais, o que está relacionado com o acentuado deslocamento de populações rurais para as cidades. Repleta de casos empíricos, a coletânea traz grande riqueza de dados, principalmente sobre a Bolívia, mas inclui também alguns dados sobre o Peru, resultando em comparações entre os dois lugares. O objetivo da autora é apresentar dados e levantar questões mais do que apontar conclusões. Este ensaio contém casos coletados entre 1994 e 2004 - o mais antigo ocorreu em 1958 e o mais recente, em 2004 - totalizando 394 casos analisados.

O primeiro capítulo, "¿Qué es creer?", foi feito a partir de dados coletados principalmente entre 2002 e 2003 por alunos da Universidade Mayor de San Andrés, La Paz, onde Alison Spedding dá aulas de antropologia e sociologia. Os alunos entrevistaram pessoas de diferentes idades, origens sociais e "níveis de crença" (:33), que fizeram consultas a yatiris - sábio que executa rituais diversos, inclusive de cura (em sentido amplo, não apenas físico), e faz prognósticos através da leitura da coca - e a curandeiros em La Paz. Pessoas que consultaram somente para comprovar se o yatiri era um "mentiroso" estavam menos propensas a seguir todas as orientações recebidas, sendo assim mais difícil alcançar o resultado desejado. De acordo com a concepção popular de magia, ainda que o rito seja perfeito e o yatiri ou curandeiro absolutamente competente, somente o cliente que tiver fé obterá algum resultado. Para a autora, é fundamental focar "nos contextos sociais que produzem a disposição a aceitar ou a rechaçar a explicação" de fatos perturbadores na vida cotidiana em termos "místicos ou coincidência ou materialismo", e "estudar em detalhe todos os aspectos dos ritos" (:35) - comportamentos, insumos, gestualidade, vínculos com outros ritos, entre outros.
O segundo capítulo, "De kharisiris y kharsutas", tem como tema uma figura muito difundida nos Andes, não apenas em regiões rurais, mas também nas cidades. Chamado na Bolívia de kharisiri, sacamantecas, lik'ichiri e, no Peru, mais de pistaco (ou pishtaku) e nakaq (ou ñak'aq), este ser [maléfico humano] busca extrair a gordura, por vezes também a medula e o sangue, de pessoas que geralmente andam sozinhas pelo campo - mas não somente - com o intuito de vendê-la para diferentes fins (lubrificar máquinas, usos médicos e religiosos etc.). As pessoas dizem que a gordura é extraída (alguns contam que se usa uma "maquininha") pelos kharisirise que, para se proteger deles, é preciso não viajar sozinho; resistir ao sono quando se está entre desconhecidos; fumar cigarro e mascar coca; comer alho; untar a cintura com o suor das axilas etc.

A partir de uma estatística dos casos, conclui-se que os homens são mais atacados que as mulheres, geralmente no período da noite e com maior frequência no mês de agosto. Outro dado importante é que os kharisiris são na maioria das vezes homens, porém nem sempre desconhecidos. Isto vai ao encontro de parte da bibliografia sobre os Andes que contradiz a difundida interpretação do kharisiri como "representação do 'Outro' colonial, étnico, dominante e/ou explorador" (:64).

Por ser pouco provável conversar com alguém que afirme ser kharisiri, sendo mais comum deparar-se com aqueles que são acusados, o que se pode encontrar mais facilmente no departamento de La Paz são os kharsutas. Assim são chamadas as vítimas dos ataques dos kharisiris, que depois de algum tempo - pode demorar até semanas - manifestam uma "doença", que tem como principais sintomas dor na região abdominal, febre, vômito, indisposição e dor de cabeça. 
O kharisiri rouba a gordura da vítima e com essa mesma substância prepara um remédio para a doença e o comercializa. De acordo com os relatos, os remédios tradicionais funcionam na grande maioria dos casos. O cuidado a ser observado é em relação ao tipo de doença que a pessoa manifesta: as tratadas pelos médicos ou as tratadas pelos yatiris - e o bom yatiri sabe distinguir entre elas. Há risco de morte quando se faz o tratamento errado (médico em vez de curandeiro, ou vice-versa). Os dados mostram que os pacientes não lidam com a "biomedicina" e a "medicina tradicional" como "dois mundos opostos e sem comunicação, mas como dois componentes de um sistema global" (:74). Tal noção revela muito sobre a relação corpo/mente entre os andinos. "Para a biomedicina, o corpo é inteiramente material [...]. Na medicina tradicional não há essa distinção. 'Alma' faz referência a tudo da pessoa que sobrevive à morte, tanto a parte que fica no cemitério como a parte que vai até Deus" (:77).

Finalmente, um dos aspectos mais importantes, a meu ver, é a questão do egoísmo, segundo a autora um dos elementos que caracterizam o kharisiri: alguém que não quer compartilhar, que se recusa a participar de cargos e atividades comunais, que não compartilha comida, enfim, atos de um "avaro". Esta é também uma característica do condenado - outra figura muito recorrente nas etnografias andinas - objeto do artigo seguinte.

No terceiro capítulo, "El condenado", uma "espécie de zumbi andino" (:11), emerge com características de um ser antissocial: dorme de dia e caminha de noite; não come apenas carne crua, mas come exatamente as mesmas partes do corpo que o tigre ou o jaguar, o predador mais temido; se recusa a dormir em casa e geralmente não quer comida cozida. Uma importante característica do con- denado, que define seu aspecto, é seu corpo apodrecido, cheio de larvas, que se desfaz literalmente.

Os principais motivos para condenarse são: fazer uma promessa de casar-se com alguém e morrer antes de poder cumprir; ter relações sexuais com um parente de primeiro ou segundo grau (mãe, pai, irmão[ã], filho[a]), ou com um parente espiritual (compadre/comadre, afilhado[a]); ter muitas dívidas e morrer sem pagá-las; ter ocultado muito dinheiro e outros bens valiosos sem falar para ninguém; morrer quando não é seu destino, o que inclui especialmente o suicídio.

Alguns autores defendem que o pecado do condenado é a falta de reciprocidade, mas para a autora este é um "abuso da palavra 'reciprocidade'" (:117), sendo usada para descrever qualquer tipo de intercâmbio. Conforme os textos apresentados, o incesto deriva da não aceitação dos pais, mais especificamente da mãe, de que seus filhos(as) busquem um(a) companheiro(a). Segundo Spedding, isto não é exatamente falta de reciprocidade, pois não receberam o filho de outra pessoa para que tenham que estabelecer uma relação recíproca, mas sim uma "negação do ciclo vital". Também é fruto de um "amor excessivo" dessa mãe pelos filhos, que não deseja se desprender deles; por isso tem uma gravidez prolongada, sendo obrigada a carregar um filho em sua barriga por sete anos.

A motivação para as condenações por dinheiro é a mesma: não querer se desprender do dinheiro. Por isso o condenado não se salva se alguém encontrar acidentalmente seus bens, pois ele deve desprender-se voluntariamente deles. Portanto, o castigo apropriado é não se desligar do corpo por mais repulsivo e apodrecido que esteja, não podendo passar desta para a outra vida; não é recebido por Deus enquanto não pagar por seus pecados. 
Na parte final do capítulo são apresentados dados sobre os condenados de Huancavelica, Peru, explicitando-se as variações estabelecidas entre o kharisiri boliviano e o pishtaco peruano. Entre elas está o fato de o condenado de Huancavelica tornar-se condenado logo após o ato, e o boliviano, apenas depois da morte. A autora finaliza ressaltando que o ponto comum no conjunto apresentado neste capítulo é o "egoísmo", tanto o "egoísmo sexual" como o "egoísmo econômico" (:133).

No quarto capítulo, "Un diccionário de los sueños", o foco é a interpretação dos sonhos, sua importância e seus diversos significados. O sonho costuma ser uma inversão do que será a situação vivida. Spedding ressalta uma diferença entre a concepção ocidental do sonho e o "sonho andino". Este possui caráter relacional, é "compartilhado", estando diretamente relacionado a uma dimensão ética e moral, noção que está ligada a um conceito que a autora chamou de "indivíduo vinculado" (:15). "O sonho andino expressa interação com os demais, o que pensam, o que estão fazendo comigo" e, ao mesmo tempo, expressa o "porvir" (:138), o que acontecerá com a pessoa que sonha. Trata-se de outro conceito de indivíduo e de psique, bem como outra noção sobre a relação que este tem com os demais.

Os dois últimos capítulos são publicados pela primeira vez nesta segunda edição do livro. No capítulo 5, "Gótico americano", a autora compara dados sobre as "cabeças voadoras" (a cabeça que se desprende do corpo e se desloca para outros lugares), obtidos através de relato oral, com informações sobre outros seres semelhantes da literatura andina, os assassinatos por decapitação que aparecem na imprensa local, e o culto, em La Paz, a caveiras (ñatitas) - devem ser de pessoas que tiveram morte violenta. A autora questiona acerca de uma possível continuidade entre o culto atual e as "cabeças troféu", as cabeças cortadas que eram representadas na arte pré-hispânica.

O sexto capítulo, "Chuqilqamiri Wirnita", é o estudo de um conto popular muito difundido nos departamentos de La Paz e Oruro, cujo personagem principal dá à luz um bebê meio humano e meio víbora, pois a mulher tem um amante que se transforma em víbora de dia. O mito tem vários elementos que aparecem em outros "contos" andinos, como a inveja gerada pelos bens materiais, os casamentos por interesse, a associação da serpente com a riqueza, a relação entre o civilizado/ conhecido e o selvagem/ oculto, a avareza, e outras questões morais.

Pela variedade, atualidade e natureza dos dados apresentados - não disponíveis facilmente em outras fontes - o livro é de grande interesse para os pesquisadores da região andina, por ampliar as reflexões acerca de seus conceitos e relações.

WEBER, Alexandre de Vasconcelos. 2012. Transmissão de patrimônio habitacional em favelas. Niterói, RJ: Editora da UFF. 277 pp.

\section{Tomás Henrique de Azevedo Gomes Melo}

Doutorando no PPGA-UFF

O livro de Alexandre Weber é resultado de sua tese de doutorado, desenvolvida a partir de aproximadamente 10 anos de pesquisas dedicadas ao tema da transmissão de patrimônios habitacionais em favelas do município do Rio de Janeiro. Seu trabalho se insere na mesma direção de outros esforços recentes para o reconhecimento de patrimônios materiais e imateriais de grupos social e politicamente marginalizados. Já no prefácio escrito por Delma Pessanha Neves, assim como nas linhas introdutórias de Alexandre 